\title{
Aunando momentos... Presencias medievales en la plástica contemporánea*
}

\author{
$M^{a}$ Dolores Barral Rivadulla \\ Universidad de Santiago de Compostela
}

\begin{abstract}
RESUMEN. Este trabajo plantea un acercamiento a la Edad Media con el vehículo de la plástica contemporánea a través del color, la forma, las iconografías, los artistas y las técnicas.

Palabras clave: Edad Media- Pintura- Arte contemporáneo- Técnicas artísticas.

ABSTRACT. This work is an approximation to the Middle Ages. The contemporary art is the conveyance for this drawing through the colour, the shape, the iconography, the artists and the artistic techniques.

Key Words: Middle Ages- Picture- Contemporary art- Artistic techniques.
\end{abstract}

Intentar aunar dos conceptos de arte tan distintos y que en principio pueden parecer casi irreconciliables, como es el caso del arte medieval y el contemporáneo, ha supuesto una experiencia única. El acercamiento al arte contemporáneo desde el conocimiento y la especialización medieval ha sido una enriquecedora tarea sobre todo por lo distinto de su metodología, por la búsqueda de campos a través los que superar la "frontera" de los estilos y las convenciones, y sobre todo por lo que ha supuesto el trabajar con artistas que poseen un rostro -en el sentido más literal del término- y que incluso han dejado testimonios, opiniones y pistas acerca de su obra, un material con el que no siempre cuenta un historiador del arte medieval.

A la hora de unificar bajo un título esta aportación se planteó una complicada búsqueda por cuanto el mismo debería condensar su intención básica. Dicho proceso quedó cerrado al lograr ser expresado a través del término "presencia", puesto que si se consulta el diccionario una de las acepciones de la palabra es el de memoria de una imagen o idea, o representa-

\section{-}

* Quiero agradecer a través de estas líneas las aportaciones que para este trabajo me han realizado mis colegas Fernando Galván Freile y Juan Ángel López Manzanares. ción de ella. Esa es la vocación de este trabajo: un acercamiento a la Edad Media con el vehículo de la plástica contemporánea a través del color, las formas, las iconografías, los artistas o las técnicas.

Uno de los problemas principales que se detecta cuando se intenta ahondar en esta relación es que entre las ideas transmitidas por la historiografía contemporánea resalta la vinculación medieval-primitivo, en algunos casos como sinónimo de ahondamiento en las raíces artísticas, pero en otros el matiz era distinto e incluso peyorativo puesto que lo medieval se convertía incluso en una excusa para justificar cierta rudeza o "fallos" en la obra plástica.

Se trataba de detectar presencias, pero como se ha comentado, no parecía tarea fácil, a la capacidad trans-histórica de la obra de arte, a esa posibilidad de vivir en muchos tiempos, se unía el problema de su recepción. Como afirmaba S. Moralejo': "a las obras de arte les es dado habitar el futuro, al igual que el hombre

\footnotetext{
${ }^{1}$ S. Moralejo Álvarez, "Prólogo" a la obra El Pórtico de la Gloria en la Inglaterra victoriana. La invención de una obra maestra, (Mateo Sevilla, M.), Santiago de Compostela, 1991, p. 11
} 
habita, en buena parte su pasado. De esas naturales relaciones anacrónicas, tenidas en otras historias por accidentes o retrógradas aberraciones, se trata aquí; de centrar la reflexión sobre los avatares que las obras de arte conocen en su perduración; las nuevas lecturas y apreciaciones de que son objeto; sus transformaciones físicas, nuevos usos e incluso reciclajes; sus degradaciones, sus eclipses y, en fin, sus venturosas recuperaciones".

El primer problema que se planteaba a la hora de recopilar e intentar unificar el material era el de darle forma conveniente, eran muchos los retazos, las ideas y las propuestas pero la característica fundamental de lo encontrado era que vagamente podría incluirse dentro de un hilo conductor común. Lo localizado eran en su mayor parte referencias cruzadas, pequeñas "pinceladas" tomadas de uno y otro lado; porque lo medieval siempre era uno más de los múltiples componentes de la obra de arte y casi nunca el principal, de ahí que se optase por presentarlo bajo cinco epígrafes de carácter más o menos general:

- La Edad Media como época: Partiendo de lo que tradicionalmente se considera como Cuadro de Historia, se han elegido algunos ejemplos con la idea de ilustrar este aspecto puesto que el tratamiento de este género en profundidad permitiría elaborar un trabajo monográfico.

- La Edad Media como motivo/ recurso/objeto: Dentro de este apartado se tratará el "objeto" medieval como principal motivo o recurso plástico. Un capítulo en el que se pueden observar diferentes perspectivas desde admiración, animadversión e incluso desde la experimentación o la neutralidad ante el medievo.

- La Edad Media como estilo, entendido este último como conjunto de características que individualizan la tendencia artística de una época. Aunque quizás en este caso sería más correcto hablar de estilos por cuanto durante el periodo medieval se asiste al desarrollo de varios. Dentro de este capítulo quizás el caso más significativo sea el de los "neos". A pesar de ello, y como se demostrará, en la época contemporánea son posibles puntos de encuentro con la Edad Media; aunque también es cierto que casi nunca ésta constituye el referente principal de la obra. En estos encuentros a veces es imposible la localización de obras medievales que puedan ejemplificar lo afirmado, porque más que de ejemplos concretos se trata de evocaciones que se funden con la raíz contemporánea para convertirse tan sólo en presencias. En otras ocasiones es posible rellenar lagunas con las ventajas que ofrece el poder "escuchar", en ocasiones, la voz del artista lo que permite precisar apreciaciones e incluso presencias de otro modo indetectables.

- La Edad Media como identidad, en este caso abordada desde el punto de vista de identidad nacional y que no siempre queda reconocido dentro de lo que solemos clasificar como "revival". Así por ejemplo mientras "Viollet-LeDuc veía el gótico como el punto en que en Francia se había desprendido de las tradiciones romanas, lo que supondrá una manifestación de galicismo y adquiriría en Francia concretas connotaciones nacionalistas. En Inglaterra, por el contrario, la opinión pública identificaba el neogótico con el arquitecto Pugin, considerado filopapista, y cualquier clase de arte que tuviese un cierto aire medieval se veía como una abierta xenofilia cómplice de la iglesia de Roma"2.

- La Edad Media como inspiración, donde se tratará la visión del Medievo desde sus personajes, su literatura etc... pero a través del un lenguaje plástico completamente contemporáneo.

Cada apartado será organizado en lo posible de manera cronológica a pesar que la visión general sea diacrónica. Esta elección se debe a que así, y al mismo tiempo, se pueden destacar las distintas propuestas y su diferente valoración según países y cronologías. Asimismo, y en la medida de lo posible, se intentará que hable el historiador del arte contemporáneo, como testimonio que tanto refrenda como discrepa de las presencias aquí combinadas.

LA EDAD MEDIA COMO ÉPOCA:Los ejemplos escogidos plantean diferentes puntos de vista. El primero es la visión de la Edad Media desde la pintura de historia pero de temática religiosa. Así, la propuesta de J. von Führich en Cruzados ante el Santo Sepulcro, 1825, (Ilustración 1) identifica una Edad Media épica y modelo a imitar conforme a las ideas de los nazarenos.

\section{-}

${ }^{2}$ S. DANESI, "La Edad Media revisitada: "The Preraphaelite Brotherhood"', El revival en las artes plásticas, la arquitectura, el cine y el teatro, Milán, 1974, p. 80 
Un caso distinto es el de E. Delacroix quien en su obra Entrada de los cruzados en Constantinopla, 1840 se presenta conforme al espíritu romántico donde la manifiesta "huida" de la realidad en ocasiones puede acudir a la evocación de un tiempo histórico pasado seleccionando casi siempre dentro del mismo un episodio en el que suele entremezclarse la historia con la leyenda. Interesa destacar también aquí la admiración que este autor sentía por lo medieval: “... seguramente el hecho que más profunda huella dejó en su estancia, en el verano de 1813, en la abadía de Valmont (Fécamp), por aquel entonces propiedad de un primo suyo (...) este primer encuentro con rincones medievales llenos de historia, nostalgia y misterio, en definitiva, con el mundo medieval que tanto influiría en su obra y en la generalidad del movimiento romántico, se completó en los primeros meses de 1814 con la visita a Rouen. La magnificencia de la catedral, el inquietante silencio de su interior, el juego de la luz que penetra por los vitrales y rasga la oscuridad de las naves, debieron de impresionar vivamente al muchacho que desde entonces mostró una ferviente admiración por la arquitectura gótica" 3 .

Un ejemplo totalmente distinto de acercamiento al mundo medieval es que el E. H. Degas plantea en sus Escenas de guerra en la Edad Media, 1865, donde frente a la "reconstrucción" historicista que habitualmente se podía contemplar en el cuadro de género se asiste a la anulación de las referencias históricas siendo tan sólo el título de la obra el nexo que la liga a esta época.

Un acontecimiento de época medieval como origen de una nacionalidad es la evocación que plantea N. Roerich en Los visitantes de tierras lejanas, 1901 (Ilustración 2). Este cuadro "forma parte de una serie que había concebido bajo el nombre El origen de Rus (...) relacionado con la leyenda del origen de la antigua Rusia (Rus en su primera época), el motivo de este cuadro es la llegada de los varengos, o como se les llama también vikingos, de "más allá de los mares", como reza la leyenda"

${ }^{3}$ Tomado de Summa pictórica, vol. IX, Barcelona, 2000, p. 190.

${ }^{4}$ N. Novosílzov, La pintura rusa. El siglo $X X$, Roma, 2001, p. 23.

\section{LA EDAD MEDIA COMO MOTIVO/ RE-} CURSO/OBJETO

Una iglesia, catedral, monasterio, o edificio de origen medieval, son motivos pictóricos comunes a una parte de la plástica contemporánea. Sin embargo, la intencionalidad de su elección no es siempre la misma.

C. D. Friedrich en su Cruz en la monta$\tilde{n} a$, ca.1811, no permite identificar la arquitectura de fondo con la tradicional visión romántica en la que las ruinas medievales aluden a cierta melancolía sobre el pasado sino que la arquitectura se mezcla con toda una alegoría religiosa profundamente protestante. En este caso sus ruinas góticas, simbolizan la fe católica apagada.

Dentro del movimiento Romántico, pero ya más acorde con la revisión que en esos momentos se está produciendo de la Edad Media, y dentro de la corriente paisajística, se encuentra la obra de J. Constable la Catedral de Salisbury, 1823. Esta pintura, parte de una serie sobre dicha catedral, se utiliza para demostrar que las cosas no poseen un color real determinado, sino sólo conceptual, intelectual, ya que la percepción del color viene matizada por la luz. En este caso la torre de la catedral se encuentra enfatizada por las ramas que remarcan y enmarcan la forma ojival, es el concepto de Naturaleza como arquitectura vegetal y que lo relaciona con las tesis contemporáneas que ven el gótico como un estilo derivado de las formas vegetales.

Por su parte, C. Corot, en La catedral de Chartres, 1830, desarrolla una obra realista que, a la vez, supone un camino abierto hacia el Impresionismo. Centrado en el estudio de la luz y de la atmósfera, y su incidencia en el color de los objetos del mundo real, la arquitectura es un componente esencial de la vista; no sólo sugiere la unidad inseparable entre civilización y naturaleza, sino que constituye el volumen sólido en el que se condensa la luz difusa del paisaje. El edificio no está encuadrado en la perspectiva de los paisajes clásicos, ni tampoco queda reabsorbido en lo "pintoresco" como en J. Constable; lo que interesa al pintor es definir un espacio pictórico unitario en el que ningún elemento adquiera más importancia, donde lo destacable sea

\footnotetext{
${ }^{5}$ P.K.SCHUSTER, "L'Allemagne et le "gothique" retrouvé", Le "Gothique” retrouvé, Exposition Hôtel de Sully, 31 oct 1979-17 fev. 1980, Paris, 1979, p. 29.
} 
tan sólo la plasticidad de los volúmenes a través de la luz.

J. Pérez Villaamil en su Pórtico de la Gloria, 1849-1850 (Ilustración 3) plantea una visión romántica del pórtico compostelano donde prima la más recreación que el dibujo arqueológico. Como manifiesta S. Moralejo: “con sus dramáticas e inverosímiles perspectivas, entreveradas de hilachas de un sol ubicuo; con sus abigarradas multitudes campesinas, posible e imaginario caldo de cultivo de la memoria "popular" de Mateo y su obra (...) por lo que respecta a la interpretación pictórica del monumento, estamos todavía lejos del rigor arqueológico y aun de una aproximación intuitiva a los valores específicos de su estilo. Demasiado clásica en la pesada articulación de sus molduras, gótica en exceso por la vibrante filigrana de arcadas y capiteles, la robusta plástica del Pórtico se ve asimilada a los ambientes flamígeros y platerescos en que Villamil definió su mejor oficio" 6 .

Un caso muy distinto es la serie que C.O. Monet dedica a la Catedral de Rouen donde un motivo tan conocido es transfigurado al ofrecer sólo un fragmento acotado del mismo y envolverlo en distintas atmósferas que, no obstante, también supone una sublimación de la tipología arquitectónica representada. Esta serie dedicada a la catedral de Rouen es calificada como la culminación de los estudios del autor. Una serie que comenzó en el año 1892 y terminó en 1894. En 1895 una veintena de estas imágenes fueron fue exhibidas en la galería de Durand-Ruel con gran éxito. C. O. Monet confesaba en el momento de la ejecución "lo arduos que le son los obstáculos que encuentra: “¡Caramba! No puedo más que repetir esto: cuanto más avanzo, menos consigo reflejar lo que siento [...] y trabajo continuamente sin progresar, buscando, vacilando, sin obtener mucho...." El portal y parte de la torre son percibidos sólo en función de las variaciones temporales y climáticas, pero también reinterpretados subjetivamente. La catedral es ya solamente un pretexto para llevar a cabo una intensa meditación que funde preferencias, sensaciones, pensamientos huidizos, y pensamientos duraderos, sentimientos secretos $\mathrm{y}$,

\footnotetext{
${ }^{6}$ S. Moralejo Álvarez, “Prólogo”, op. cit., pp. 18-19
}

finalmente, una metafísica que pertenece sólo al pintor"

R. Delaunay dentro de su particular interpretación del cubismo muestra su Saint Séverin, 1911, (Ilustración 4) como una transición entre la figuración y la abstracción geométrica. En este caso "el tema, desempeña un papel absolutamente subordinado, pero está en estrecha relación con la idea que en él se llega a expresar, ya que el artista elige siempre aquello que es capaz de expresar la idea de manera más sencilla. El primer estadio en este desarrollo viene caracterizado por el cuatro St. Séverin. La intención del artista es concentrar la mirada del observador en el centro del cuadro (...) mediante una dinámica espacial paralela, que se da por la debida distribución y correspondencia de los colores, así como por la tendencia al movimiento de las curvas correspondientes" ${ }^{, 8}$.

El edificio medieval como motivo sin trascendencia aparente aparece en obras como en La iglesia de Auvers, 1890, de V. van Gogh; la obra naif de B. Vivin, Catedral de Reims, o, dentro de la plástica gallega, se detecta ejemplos como El Pórtico de la Gloria, 1942 de L. Martínez Villafínez, o el Monasterio de Caaveiro, 1950 de U. Lugrís.

Para cerrar este apartado se ha elegido el ejemplo excepcional del diseño que W. Kandisnky elabora para Der Blaue Reiter, 1912. Donde un motivo medieval pasa a primer plano como tema. "San Jorge es el motivo definitivo que ocupará el estudio definitivo para la portada del almanaque (...) al pie del caballo aparece aquí la princesa encadenada que según la leyenda debe ofrecerse como víctima al dragón. Del propio dragón sólo se entrevé la cola con manchas. La lucha contra el dragón es un tema muy frecuente tanto en la pintura rusa de iconos como en los exvotos bárbaros. W. Kandinsky realizó siempre variaciones nuevas sobre el motivo de la figura matando al dragón" ${ }^{\prime 9}$. El Blaue Reiter, figura clave en la iconografía de W. Kandinsky, identifica el papel de vencedor en lo material y en lo físico. El motivo del jinete

\footnotetext{
7 "El impresionismo en piedra", Los impresionistas y los creadores de la pintura moderna. Degas-CézanneMonet-Renoir, vol 2, Roma, 1999, p. 171.

${ }^{8}$ E.V. Busse, "Los medios de composición en Robert Delaunay", El jinete azul, Barcelona, 1989, pp. 99-103, p. 101 para nota.

${ }^{9}$ U. BECKS-MALORY, Kandinsky, Colonia, 1999, p. 89.
} 
aparece en su obra desde los comienzos y a través de múltiples variantes, como figura romántica de cuento "caballero medieval que encarna las virtudes, mensajero enigmático, un heraldo tocando la trompeta o como un San Jorge que salva a la humanidad del mal"10.

LA EDAD MEDIA COMO ESTILORetomando algunas de las ideas planteadas al principio, este capítulo comienza a componerse a partir de retazos (donde en ocasiones serán los propios autores los que expliquen las conexiones entre sus obras y el medievo) hasta llegar a los "neos" tanto los históricos como los más actuales y quizás por ello más controvertidos.

\section{Del color y las formas}

Inician este apartado dos obras de P. Gauguin, Cristo amarillo, 1889, y Visión después del sermón, 1888. En la primera no sólo destacan ciertos préstamos del arte primitivo como el hieratismo, las formas o los colores que son pesados, compactos e intensos- sino que también mantiene determinados motivos iconográficos tradicionales aunque a estos se le sustrae su significado tradicional, convirtiendo la imagen religiosa en un ídolo. Es cierto que en las pinturas de temática religiosa se aprecia durante mucho tiempo el mantenimiento de ciertos parámetros iconográficos que incluso arrancan de época medieval, quizás por una cierta prevención a lo que podría constituir una alteración del significado original de la imagen. Como afirma J. Plazaola: "la resistencia a admitir cierta imaginería actual que se advierte en ciertos sectores se debe al disgusto o desorientación que les produce el quebranto o abandono de lo que se concibe como "respeto a la anatomía natural" de los personajes efigiados" $"$.

En el segundo ejemplo - Visión después del sermón - se utiliza el color como en la Alta Edad Media, los esmaltes o las vidrieras, es decir, de un modo arbitrario, dando lugar a un entramado bidimensional donde se ha eliminado el plano intermedio. El color tiene, en consecuencia, una función local y es aplicado en áreas planas de contornos muy definidos. Un modo de concebir el color que sin duda hunde sus raíces en lo medieval pero también en lo primitivo y lo oriental. Este modo de hacer, común a P. Gau-

\footnotetext{
-

${ }^{10}$ IDEM, p. 20

11 J. Plazaola Artola, Historia del arte cristiano, Madrid, 1999, p. 300
}

guin y los pintores de Pont-Avent - en el que, "las formas tratadas con colores puros dispuestos bidimensionalmente quedan encerradas por líneas negras que acentúan la separación entre el objeto pictórico y el fondo, pero no por criterios de perspectiva sino por la sintética delimitación de las cosas y las figuras (...)- fue rechazado por creadores como Cézanne, para quien, tal como explica E. Bernard en Souvenirs de Paul Cézanne "Gauguin no fue un pintor, no hizo más que chinoiseries" y para quien "señalar los contornos de superficies coloreadas con un trazo negro es un defecto que debe evitarse a toda costa", 12 .

Dentro del expresionismo alemán E. Nolde presenta determinadas escenas evangélicas, como La última cena, 1909, concebidas desde una característica violencia cromática ${ }^{13}$, de un rudeza tan intensa y visionaria que enlazan con la pintura medieval germánica, pero con la utilización de recursos pictóricos modernos en la textura y en el color encendido. Sus profundas creencias religiosas serán la fuente de inspiración de la mayor parte de su pintura.

Dentro del expresionismo es necesario mencionar a E. L. Kirchner, uno de los fundadores de Die Brücke, quien defiende el carácter atemporal del expresionismo ${ }^{14}$ identificando gótico-germánico. Este autor afirma: "ique fundamentalmente distinto es el arte germánico del arte románico! (...) el arte románico obtiene su forma del objeto, de la forma natural. El artista alemán crea la suya a partir de la imaginación, de la visión interior, y las formas de la naturaleza visible sólo son símbolos para él ... para el artista románico la belleza se encuentra en las apariencias; el otro la ve detrás de las cosas"15. Estas ideas se materializan en ejemplos como su Paisaje con luna invernal, 1919, al respecto del que afirma "no es correcto juzgar mis cuadros de acuerdo con la norma de la fidelidad a la

12 Summa pictórica..., op. cit., vol. IX, p. 288

13 J. PlazAOLA ARTOLA, op. cit., p. 282

14 "El expresionismo, en un sentido amplio es un fenómeno intemporal en el arte. Se encuentra entre los habitantes de las islas del Pacífico, en los aztecas, en África y en las catedrales góticas, en las ilustraciones de los manuscritos medievales: en Grünewald y en el Greco. La profundidad espiritual y la conexión con lo metafísico, lo invisible y lo intangible, han caracterizado a la pintura y a la escultura alemana desde sus primeros tiempo. Pero esto sólo forma parte de la historia. El expresionismo alemán de principios de siglo fue un arte comprometido". K. RUHRBERG, Arte del siglo $X X$, vol. 1. Pintura, Barcelona, 1999, p. 54.

${ }^{15}$ K. RUHRBERG, op. cit., p. 56. 
realidad, porque no son retratos de objetos o seres concretos, sino que más bien son organismos independientes por sí mismos, compuestos de líneas, planos y colores. Sólo contienen formas naturales en la medida en que éstas son la clave necesaria para comprenderlos. Mis cuadros son alegorías, no retratos" $" 16$.

Otro de los máximos representantes del expresionismo, pero en este caso francés, es G. Rouault cuya formación de vidriero siempre dejará una impronta en sus obras como Santa Faz, 1933 (Ilustración 5), donde no sólo mantiene las formas sino incluso la imaginería medieval. El propio autor justificaba su obra diciendo "si hubiera habido bellas vidrieras como antaño en la Edad Media, quizá no habría sido pintor" ${ }^{, 17}$ de hecho también ejecuta las vidrieras de la iglesia de Plateau d'Assy.

La influencia de la pintura románica y de la sencillez gótica catalanas siempre han sido referencia constante en las obras que tratan sobre la obra de J. Miró. Como afirma J. Dupin "sobre todo se encuentra turbado desde la infancia por la extraordinaria libertad y la fuerza visionaria de los frescos románicos, su violencia expresiva, su fantástica trasmutación de lo real. En contraste, la arquitectura gótica catalana le cultiva el gusto por los espacios desnudos, despojados, austeros, que se harán frecuentes en ciertos ciclos de su pintura" ${ }^{\text {"18 }}$.

Esta influencia medieval también puede rastrearse a través de las conversaciones que el artista mantiene con G. Raillard. Así, a la pregunta: ¿el Museo de Montjuic fue su primer museo?, J. Miró contesta: "Si a los ocho años, a los diez, iba solo el domingo por la mañana al Museo de Arte Románico. Me trastornaba. Además de los frescos románicos que usted ya conoce, había una sala de reproducciones de los frescos de las grutas prehistóricas, y no los he olvidado"19. Estas fuentes de inspiración quedan patentes en la utilización del color en su periodo fauvista.

\footnotetext{
${ }^{16}$ K. RUHRBERG, op. cit., p. 55

${ }^{17}$ J.L. FERRIER, El arte del siglo XX. 1950-1990, Barcelona, 1990, p. 101

18 J. DupIN, "Miró y la realidad catalana", Càntic del sol, Exposición Museo del Patio Herreriano, Valladolid, 2003, pp. 14-25, p. 16 para nota.

${ }^{19}$ G. Raillard, Conversaciones con Miró, Barcelona, 1993, p. 25
}

Otro ejemplo de su vinculación a lo medieval es el de su obra Tierra Labrada, 1923-24, sobre la que también conversa con G. Raillard. Ante la cuestión de si la misma preconiza el surrealismo, el artista responde: "por completo. Para mi un árbol no es un árbol, una cosa que pertenece a la categoría vegetal sino una cosa humana, algo vivo. Un árbol es un personaje (...) Usted ya sabe que a veces pongo un ojo o una oreja en los árboles. El árbol ve y oye En los frescos románicos de Montjuich hay animales constelados de ojos (...) Me impresionaron mucho esos frescos. Es formidable. Hasta los ángeles tiene ojos por todas partes" ${ }^{, 20}$.

Dentro de esta línea de conexión con la Edad Media al referirse a su obra La Granja, 1921-1922, afirma: "para mi una brizna de hierba tiene más importancia que un gran árbol, una piedrecilla más que una montaña, una libélula es tan importante como un águila. En la civilización occidental es necesario el volumen. La enorme montaña es la que tiene todos los privilegios. Pero en los frescos romanos se encuentran animales que tienen gran importancia. He observado con frecuencia esos frescos porque todos los domingos por la mañana, cuando era chico, iba al Museo de Arte románico de Montjuich" 21 .

A una estética totalmente distinta remite la obra del pintor ruso asociado a los círculos cubo-futurista D. Burlik ${ }^{22}$, en cuyo Retrato del poeta futurista Vasili Kámenski, 1917, el color y las formas recuerda sin duda a los iconos rusos. La representación frontal, las luces, el halo y las inscripciones junto con el paisaje estilizado remiten a esta importante fuente de inspiración aunque la contemporaneidad de la obra se hace patente a través de la lectura de la leyenda del nimbo donde se indica: "rey de los poetas, cantor-guerrero futurista, Vasili Vasilevich Kámenski, año 1917, republica Rusia”, y a la derecha, bordeando la cabeza, están inscritos los versos del poeta. En el extremo inferior derecho

\footnotetext{
${ }^{20}$ G. RAILLARD, op. cit., pp. 72-73.

${ }^{21}$ IDEM, op. cit., pp. 70-71

22 "pintor, diseñador gráfico e ilustrador, miembro y expositor de organizaciones como "Jota de diamantes", "Blaue Reiter", "Unión de juventud" y Salón de independientes de 1914. (...) Se le asocia con los círculos literarios cubo-futuristas, cuyos miembros (...) deben algo de su fama a la propaganda que les hizo y a la enérgica actividad que desarrolló para lanzar el movimiento futurista ruso". N. NOVOSílzov, op. cit., p. 63
} 
se lee: "hecho del original", firmado D. Burlik",23.

\section{De las técnicas}

En la búsqueda de la expresión puede decirse que la mayoría de artistas de Die Brücke se sintieron fuertemente atraídos por la técnica de la xilografía aprovechando la importancia que el Jugendstil daba a los oficios manuales frente a la mecanización ${ }^{24}$. Por ese motivo, realizan numerosos grabados en los que el lenguaje agresivo de líneas quebradas y ángulos agudos resulta más patente que en la pintura. Más que una técnica es una forma habitual de expresar y de comunicar mediante la imagen. E. Heckel se acercará a la xilografía medieval, provocando una violencia de contrates entre planos y relieves para lograr mayor expresión como en su obra Mujer orando, $1908^{25}$.

A partir de la segunda mitad del siglo XIX se asiste a un progresivo renacimiento del mosaico como arte monumental y como expresión artística autónoma. Hasta ese momento, y a excepción del momento bizantino, el mosaico era una técnica subordinada a la pintura. En Francia el pintor italiano G. Severini inicia un movimiento vanguardista en la realización de sus murales y mosaicos parietales con la técnica bizantina, dando cobertura a diversos artistas como M. Chagall e I. Zark ${ }^{26}$.

Evidentemente, sólo en un clima de fermento cultural, como el de comienzos del siglo $\mathrm{XX}$, la potencialidad expresiva del mosaico será reconocida e incluso demandada por autores como J. M. Olbrich, quien los utiliza en la decoración de la cúpula del Palacio de exposiciones de Darmstad, 1907. En ésta, "de los motivos vegetales del mosaico (distantes de las líneas sinuosas y orgánicas de Horta, y que recuerdan aquí más claramente el mundo bizantino) podrían muy bien surgir los símbolos de los cuatro evangelistas" $" 27$.

Sin embargo, será el Art Nouveau el que contribuya a ejecutar la obra artística en todas

23 IBÍDEM.

${ }^{24}$ SH. BEHR, Expresionismo, Hong Kong, 2000, p. 23.

${ }^{25}$ K. RUHRBERG, op. cit., p. 55

${ }^{26}$ D. ITURGAiz, "Materia y espíritu del mosaico", Ars Sacra, 1,1997, pp. 47-60, p. 51 para nota.

27 J. NigRo COVRE, "El revival en Austria y en Alemania de la Secesión vienesa a la fundación de la Bauhaus", El revival..., op. cit., p. 172. las técnicas. También G. Klimt a partir de su abandono de la Sezession (1905) comienza una etapa caracterizada por su obras sobre fondo de oro, una forma de expresión que le viene dada por ser "hijo de un artesano dorador al que precisamente debe su atracción por los efectos reales de ese material inalterable, que ya le fascinó en los mosaicos de Ravena"28 . Como afirma J. L. Ferrier, "el bizantinismo de Klimt no sólo se da por efectos particulares, como la estructura en tríptico de su cuadro Las tres edades o el uso del mosaico de pared, sino por el carácter fundamental de su pintura, refinadamente distanciada y por su tensión a rellenar todos los espacios con elementos decorativos que constituyen, asimismo, símbolos abstractos y alegorías" ${ }^{, 29}$. Esto se refleja en los Frisos de mosaico del palacio Stoclet, 1905-1909, donde "mediante un juego magnífico de racimos de volutas doradas y la yuxtaposición de formas geométricas estilizadas que hacen referencia manifiesta al mosaico bizantino"30. En el caso de su obra El beso, 1907-1908, el mosaico sigue presente aún en el lienzo "donde la unión e interpenetración de los amantes cuyos símbolos abstractos amplifican, al simplificarlo, el misterio casi sagrado. De este modo logra dar una dimensión intemporal a obras que la ausencia de perspectiva y la supresión de las sombras hacen parecer primitivas y religiosas"31.

\section{Ejemplos de neomedievalismo}

\section{Francisco Asorey y el arte románico}

En este autor gallego el acercamiento a la Edad Media se realiza desde distintas perspectivas y su fuente va desde la Puerta de Platerías al Pórtico de la Gloria. La relación del autor con lo medieval ha sido ampliamente estudiado por R. Otero $^{32}$ por lo que este autor se convertirá en referencia básica de este apartado. La vinculación entre su obra y la Edad Media pueden ser simbólica -como en el caso de la relación establecida entre los basamentos del Pórtico de la Gloria y los del monumento a San Francisco o

\footnotetext{
28 J.L. FERRIER (dir.), El arte del siglo XX. 1900-1949, Barcelona, 1990, p. 92

29 J. NigRo COVRE, op. cit., p. 171.

${ }^{30}$ J.L. FERRIER, op. cit., p. 92.

31 IBIDEM

32 R. OTERO TÚÑEZ, "El arte románico y el escultor Asorey”, Cuadernos de Estudios Gallegos, 17,1962, pp. 251273.
} 
Curros Enríquez ${ }^{33}$ - o convertirse en arquetipo, bien entendido que su lectura se postula desde una estética contemporánea.

Uno de los primeros ejemplos en los que se visualiza la influencia compostelana es en Mater, ca. 1916, (Ilustración 6) aunque "Asorey engade a súa específica visión dun artista nos anos iniciais do noso século: sobriedade de volúmenes, escuetamente novecentistas ; e triunfo dun primitivismo, cheo de vital seiva contemporánea" ${ }^{34}$. Según R. Otero las influencias en esta obra proceden de la fachada de Platerías y de la conjunción de cuatro figuras: en la disposición de las piernas coincidiría con el David y la Mujer con el león - a la que él denomina la Doncella de Toulouse-, el tratamiento del pecho y de los pliegues de la túnica en la zona superior arrancaría de la concepción de Mujer con el león y la que porta el cráneo; mientras que el tratamiento de la túnica procedería de las dos mencionadas y de la mujer cabalgando sobre el grifo ${ }^{35}$. Sin negar estas relaciones creo que sería preciso tener en cuenta también la relación de la Mater con la imagen de la Virgen en la Huída a Egipto (en el friso de Platerías) donde además de mantener el tipo de disposición de pierna cruzada detalles tan significativos como la colocación de la manos de la mujer o la disposición del niño coinciden.

A pesar de esta evidente influencia de estilo, como afirma de nuevo R. Otero, “quizá la obra de Asorey de aspecto más románico sea el Altar para el presbiterio de la iglesia y panteón social del Centro Gallego en Buenos Aires", 1944, donde cabe hablar ya, siguiendo a este autor, de un neorrománico donde el recuerdo del parteluz del Pórtico de la Gloria es el modelo referencial de la parte central del conjunto ${ }^{36} \mathrm{y}$ desde luego de su policromía ${ }^{37}$.

-

${ }^{33}$ R. OTERO TÚÑEZ, op. cit, p. 254

${ }^{34}$ R. OTERO TÚÑEZ, "O escultor Asorey. Vida e Obra", Centenario Francisco Asorey, Santiago de Compostela, 1989, pp. 23-77, p. 47.

${ }^{35}$ R. OTERo TÚÑEZ, “El arte románico...”, pp.252-253.

${ }^{36}$ R. OTERO TÚÑEZ, "El arte románico...”, p. 255. Sobre el tratamiento de la decoración del árbol de Jessé, véanse páginas 255 a 257.

${ }^{37}$ R. OTERO TÚÑEZ, “O escultor...”, p. 65. De hecho la disposición de la imagen de la Trinidad del capitel del parteluz del Pórtico compostelano se mantiene como modelo de algunas imágenes marianas como la Virgen de Guadalupe de Rianxo, la Virgen de los Desamparados, de Buenos

\section{El Gothic Revival}

Dentro de este subapartado se atenderá sobre todo al caso británico pues este movimiento carece de los elementos identificadores de carácter nacionalista del mundo francés. La presencia medieval puede rastrearse a través de un amplio número de figuras, pasando desde la ilustración de W. Blake hasta J. Ruskin y W. Morris quienes propondrán el retorno al mundo medieval, el abandono de la máquina y el desarrollo del artesanado como alternativa a la civilización industrial.

El caso de W. Blake puede ejemplificarse a través de obras como la Imagen del Rey Sebert, realizada hacia 1775 (Ilustración 7). Esta ilustración, ejecutada a pluma, acuarela y oro, fue incluida en el volumen II de Vetusta Monumenta publicado en 1789. Dicha obra representa la pintura mural situada sobre la tumba de un legendario rey inglés en el presbiterio de la abadía de Westminster atribuida a Thomas de Durham (pintor de comienzos del siglo XV). El interés de W. Blake por el arte gótico se centra en sus cualidades formales que exige una simplicidad y pureza de líneas ajena a los artistas contemporáneos $^{38}$.

W. Morris, hombre de carácter polifacético se dedicó fundamentalmente al diseño siendo su única pintura el retrato de su mujer como Reina Ginebra, 1858, y donde interesa sobre todo el tratamiento decorativo de los ambientes e incluso de las vestiduras. Por su parte J. Ruskin destacó por su polifacética actividad como escritor, pintor crítico de arte y reformista que dirigió en buena medida los gustos de la sociedad victoriana. Su obra ilustra la preocupación por el mundo medieval y su propuesta de la arquitectura románica y gótica, remitiendo al mundo artesanal en un contexto histórico que está generando las primeras arquitecturas vinculadas a los ingenieros, donde el hierro y el cristal comienzan a hacer su aparición. Sus ideas son recogidas en Las siete lámparas de la arquitectura y Las piedras de Venecia.

Algunos "neo" más actualesTan solo se han elegido para ilustrar este subapartado dos

Aires o la Virgen del Carmen del Museo de Bellas Artes de La Coruña. R. OTERO TÚÑEZ, "El arte románico...”, p. 259

${ }^{38}$ F. CAREY, "Anglaterre: "Gothic revival» en Le "Gothique” retrouvé, op. cit., p. 22. Véase también R. LISTER, The paintings of William Blake, Cambridge, 1986, obra $\mathrm{n}^{\circ} 1$. 
ejemplos que considero significativos de cómo la Edad Media aún sigue siendo referente en los albores del siglo XXI. El primer caso es la realización de Códice Alcaíns, Editado por Moleiro en el año 2000 que supone una versión actualizada de los Beatos medievales. Su autor $-\mathrm{J}$. Alcaíns- afirma "Yo únicamente he elegido ser un seguidor de todos ellos, distanciado en el tiempo, pero no demasiado en la concepción de esta pintura de colores planos, contrastados, de líneas nítidas y bandas irreales. Ahí quedan sus páginas" ${ }^{39}$.

En este acercamiento a la presencia de lo medieval cobraron en su momento una "controvertida" actualidad los frescos de la catedral de la Almudena en Madrid, un caso peculiar en el que una construcción neogótica con cripta neorrománica, encerrada en un exterior neoclásico, presenta una pinturas y vidrieras en su ábside de estilo neobizantino obra de K. Argüello. Sin entrar en valoraciones acerca de las mismas, tan sólo cabe destacar que su relación con la Edad Media no es tan sólo formal, estética, de contenido o lectura sino que la técnica utilizada en la elaboración de colores fue la medieval ${ }^{40}$.

\section{LA EDAD MEDIA COMO IDENTIDAD}

Dentro de este capítulo resulta muy sugerente el acercamiento a los renacimientos o revivals que significan dentro de la Historia del Arte la reutilización de formas o la recreación del estilo, del gusto, o de la estética de una civilización o cultura anterior. El revival es un fenómeno relacionado con el pensamiento histórico, si bien rehuye todo juicio, negando la separación existente entre la dimensión del pasado y la del presente ${ }^{41}$. Generalmente se considera revival aquel período caracterizado por el prefijo "neo" 42 . Aunque el uso del término revival en el arte occidental remite de un modo muy espe-

\footnotetext{
39 Tomado del comentario del propio autor en www.moleiro.es

${ }^{40}$ Sobre este tema puede consultarse el trabajo de D. FrAGA SAMPEDRO, "Arte y fe: aportaciones de la plástica contemporánea", La transmisión de la fe: la propuesta cristiana en la era secular, Santiago de Compostela, 2005, pp. 371-392.

${ }^{41}$ G.C. ARGAN, "El Revival", El pasado en el presente. El revival en las "artes plásticas, la arquitectura, el cine y el teatro, Barcelona, 1977, p. 7.

${ }^{42}$ G.C. ARGAN, "Il concetto di revival", Il neogotico nel XIX e XX secolo. Atti del convegno celebrado en L'Università degli Studi di Pavia, Pavia, 1985, Milano, 1989, pp. 27-33.
}

cífico a los movimientos que se producen a partir del siglo XVIII. Es necesario señalar como tanto en el mundo antiguo como en el medieval se experimentaron de un modo cíclico momentos en los que se practicó "la elección de un pasado como un momento arquetípico del presente" 43 .

El gótico, estilo característico del tardomedievo, es asumido, desde el XVIII y sobre todo en el XIX con el neogótico, como el emblema de todo el medievo, aunque hay que considerar que, en muchos casos, sus límites han trascendido la división convencional de la Edad Moderna ${ }^{44}$. La valoración positiva que adquiere la arquitectura gótica a partir de mediados del siglo XVIII es tal que merece un tratamiento individualizado. No sólo por lo que supuso como reivindicación de un estilo, sino por la propia visión que de éeste se ofreció y que llevó incluso a tergiversar su verdadera esencia $^{45}$. En casi todos los países europeos, aunque con unas diferencias cronológicas que oscilan entre los siglos XVII y XIX, se puede apreciar, como ha señalado L. Grodecki, un esquema de evolución similar con respecto al arte gótico ${ }^{46}$. Sin embargo, en este capítulo tan sólo cabe tratar el caso francés, puesto que, como se ha mencionado, es en este país donde adquiere matices de identidad nacional.

Las fases del descubrimiento del gótico en Francia son diversas. El interés arqueológico francés por el arte monumental, la escultura y la pintura mural se cristalizará en los denominados Viajes Pintorescos ${ }^{47}$. En estos las ruinas, además de incitar a la meditación, suscitarán la reflexión acerca de la salvaguarda del patrimo-

\footnotetext{
${ }^{43}$ R. AssunTo, "El revival y el problema del tiempo", El pasado en el presente. El revival en las "artes plásticas, la arquitectura, el cine y el teatro, Barcelona, 1977, p. 35.

${ }^{44}$ R. Bossaglia, "Introduzione. Ragioni e modi del neogotico. Ragioni e caratteri di un congresso" en $\mathrm{Il}$ neogótico, op. cit., pp. 13-25.

${ }^{45}$ Sobre ello véase P. ZuMTHOR, Parler du Moyen Age, Paris, 1980, pp. 49-72.

${ }^{46}$ L. GRODECKI, "Introduction", Le "Gothique" retrouvé, Exposition Hôtel de Sully, 31 oct 1979-17 fev. 1980, Paris, 1979, pp. 7-15.

47 Así aparecen obras como la de Tavernier de Junquieres, le Château de Pierre-fonds (Oise) en ruines, incluida en Voyage pintoresque de la France, t. VI, pl. IX, 1874. Este castillo, de finales del siglo XIV, será reconstruido por Viollet le Duc y será unos de las ruinas más visitadas por los pintores de finales del siglo XVIII y comienzos del XIX. E. VERGNOLLE, "Les voyages pittoresques", Le "Gothique" retrouvé, op. cit., pp. 105-109, ficha p. 110.
} 
nio que se materializará en las primeras campañas de restauración a comienzos del siglo XIX. En opinión de L. Grodecki, el apoyo estatal fue la consecuencia directa y lógica de todo el movimiento de redescubrimiento de la Edad Media que cristaliza en Francia alrededor del Musée des Monuments, y que constituyó la herencia más importante del romanticismo neomedieval del primer tercio del siglo $\mathrm{XIX}^{48}$.

Con todo, hubo otras formas de la moda neogótica, como el denominado "gusto trovador", que puede ejemplificarse en la obra de J. D. Ingres, Paolo et Francesca, 1819, (Ilustración 8) que plasma el tema de los amores culpables de sus protagonistas relatados en la Divina Comedia de Dante pero tratado como una escena de género. En la escena Paolo y Francesca recuerdan a los primitivos flamencos en el color y en el estilo, constituyendo una prueba del profundo romanticismo de J. D. Ingres, "qui s'épanouit dans ses portraits et une grande partie de son oevre orientalisante ou même "neoclassique" 49 .

Esta identidad "nacional" con lo medieval también parece contenida en la foto institucional del Grupo Tahull (Ilustración 9) realizada por Francesc Cátala Roca en 1955 ante los frescos románicos de Tahull y en la que aparecen en la que aparecen J. Muxart, J. Guinovart, J.J. Tharrats, M. Aleu, A. Tàpies, M. Cuixart y J. Mercadé. "El grupo no acuerda nada ni redacta ningún manifiesto; en él se integran artistas abstractos y neofigurativos. No hay ninguna ideología común entre ellos, pero resulta un bloque sólido y prometedor de jóvenes pintores catalanes" ${ }^{, 50}$ por lo que se nos escapa el contenido fundamental que explicaría tal fotografía, aunque la intencionalidad aquí planteada bien valdría como hipótesis.

\section{LA EDAD MEDIA COMO INSPIRACIÓN}

En este apartado, como se ha comentado, se tratará la visión del Medievo desde sus personajes o su literatura pero a través de un lenguaje completamente contemporáneo, por lo

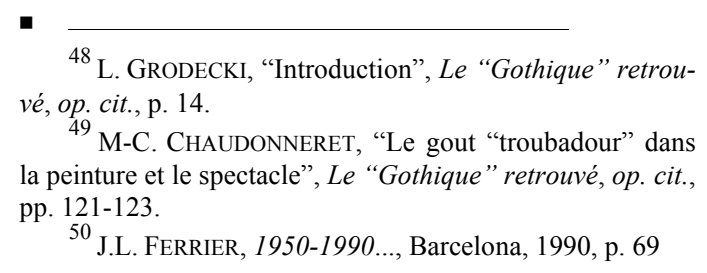

${ }^{48}$ L. GRODECKI, "Introduction", Le "Gothique" retrouvé, op. cit., p. 14.

${ }^{49}$ M-C. CHAUDONNERET, "Le gout "troubadour" dans la peinture et le spectacle", Le "Gothique" retrouvé, op. cit., pp. 121-123.

${ }^{50}$ J.L. FERRIER, 1950-1990..., Barcelona, 1990, p. 69

tanto su presencia es intangible y sólo se ciñe al campo de la inspiración.

Las manifestaciones que tienen cabida bajo este título pueden ser muy variadas aunque tan sólo se han elegido dos ejemplos. El primero es la ilustración de la Divina Comedia de Dante, que recibe un tratamiento plástico diferenciado prácticamente en cada una de las etapas del arte contemporáneo. Así por ejemplo, W. Blake en su Beatriz en el carro y Dante (1824-1827) da forma a un pasaje del Purgatorio desde un estilo inconfundible donde la imaginación y el ataque a la visión tradicional del mundo son constantes, dando lugar a un arte visionario ${ }^{51}$.

El segundo caso a valorar se centrará en la figura de San Francisco de Asís, un modelo individual que ha trascendido a través de las épocas no sólo como santo sino también como hombre. Algunas de las manifestaciones plásticas inspiradas en la figura del Poverello coinciden con la celebración en 1927 del VII Centenario de su muerte, así se erige el monumento ideado por G. Tonnini ante la basílica de San Juan de Letrán donde se representa simbólicamente su estigmatización.

Dos piezas singulares aparecen vinculadas a la plástica gallega y a la figura de F. Asorey. Una talla del santo que le valdrá la Primera Medalla de Escultura en la Exposición Nacional celebrada en el monasterio de Oseira en 1926, y el monumento levantado ante la iglesia franciscana compostelana. Con respecto a la primera de la sobras mencionadas dejemos que sean las palabras de R. Otero las que nos la interprete: "a formidable, a maxistral, a estupefacente talla de San Francisco supera todos os recursos naturalistas (...) representa o triunfo do inxénuo e primitivo, a mística valoración do espiritual, a plenitude dun estilo que fai da policromía (...) o mías eficaz complemento",52.

El Monumento a San Francisco, (Ilustración 10) "no é só o punto culminante da súa estauaria relixiosa, senón tamén duna serie de monumentos civís, dos que as directrices encaixan dentro das concepcións sociais e expresionistas da nosa época, pero sempre coa xenialidade peculiar do insigne escultor" ${ }^{53}$. Esta obra fue comenzada a construir en 1926 e inaugurada

\footnotetext{
${ }^{51}$ R. LISTER, op. cit., obra ${ }^{\text {o }} 59$.

52 R. OTERO TÚÑEZ, “O escultor...”, op. cit., p. 52.

${ }^{53}$ R. OTERO TÚÑEZ, “O escultor...”, op. cit.,p. 54
} 
en 1930, Asorey concibe el monumento como un alegoría de la vida de San Francisco, desde el mundo terrenal representado en la base, el momento histórico de San Francisco en el centro, mientras que en la parte superior se identifica la escena de la estigmatización acompañado por las alegorías de las virtudes franciscanas.

Quizás la más singular manifestación plástica vinculada al santo y pensamiento franciscanos es la que los relaciona con uno de los pintores españoles más magistrales, J. Miró. Esta relación surge a partir del encargo, en el un santo y poeta al que siempre había admirado" ${ }^{24}$, logrando una interconexión muy viva entre imagen y texto. Porque, como san Francisco, J. Miro "vio todos los elementos del universo físico como manifestaciones del amor de Dios y de su voluntad creadora, así también Miró expresó de forma reiterada una devoción casi religiosa por los detalles aparentemente accidentales del mundo natural" ${ }^{\prime 55}$. año 1975, al artista por parte del editor G. Gili de la ilustración del poema de San Francisco Cántico del sol. J. Miró creará para la ocasión una serie de imágenes "a través de las cuales (...) intentó dar forma y expresión a las palabras
${ }^{54}$ R.S. LuBAR, "El Càntic del sol y el mundo como imagen", Càntic del sol, op. cit., p. 65.

${ }^{55}$ R.S. LUBAR, op. cit., p. 67. 


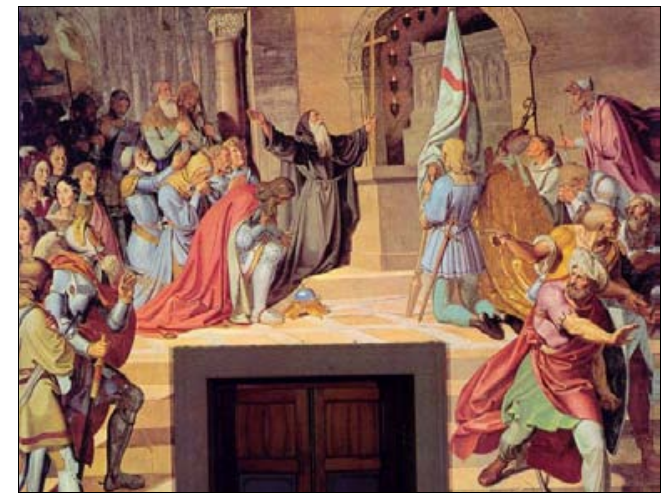

- Ilustr. 1. J. Führich, Los cruzados ante el Santo Sepulcro, 1825.

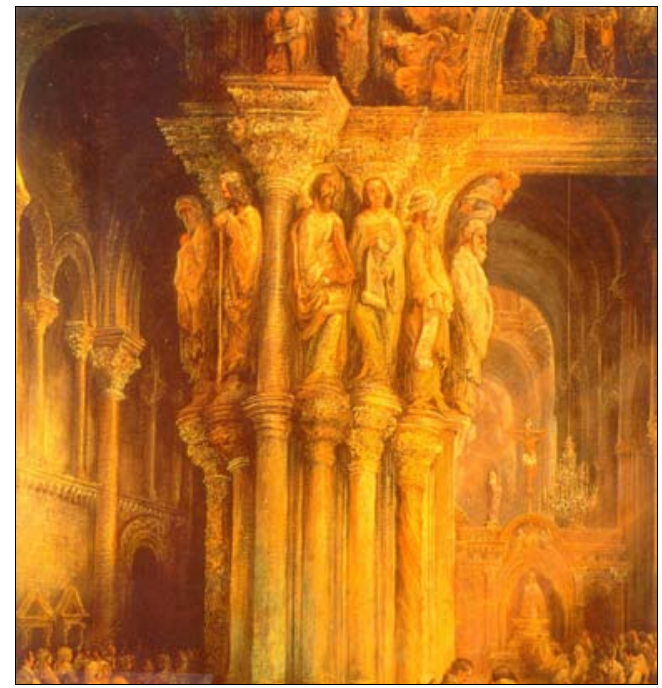

- Ilustr. 3. J. Pérez Villaamil, Pórtico de la Gloria (detalle), 1849-1851.

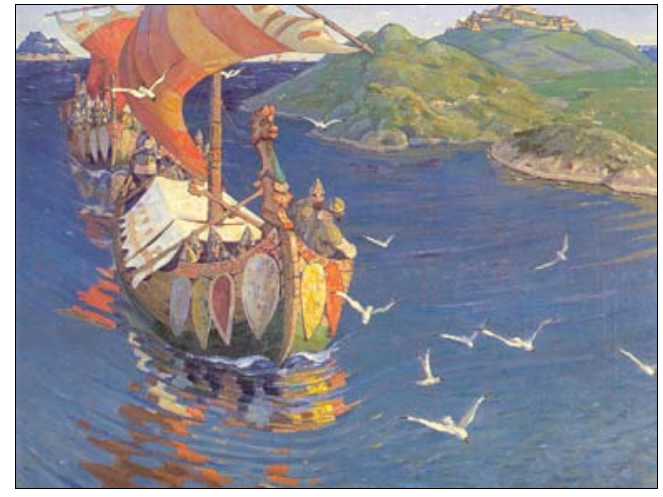

- Ilustr. 2. N. Roerich, Los visitantes de tierras lejanas, 1901.

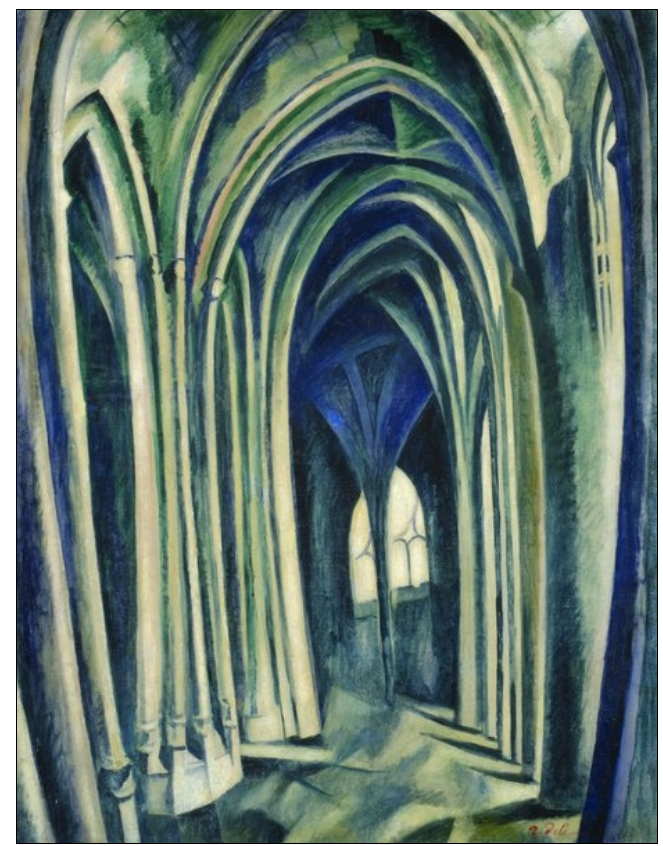

- Ilustr. 4. R. Delaunay, Saint Séverin, 1911. 


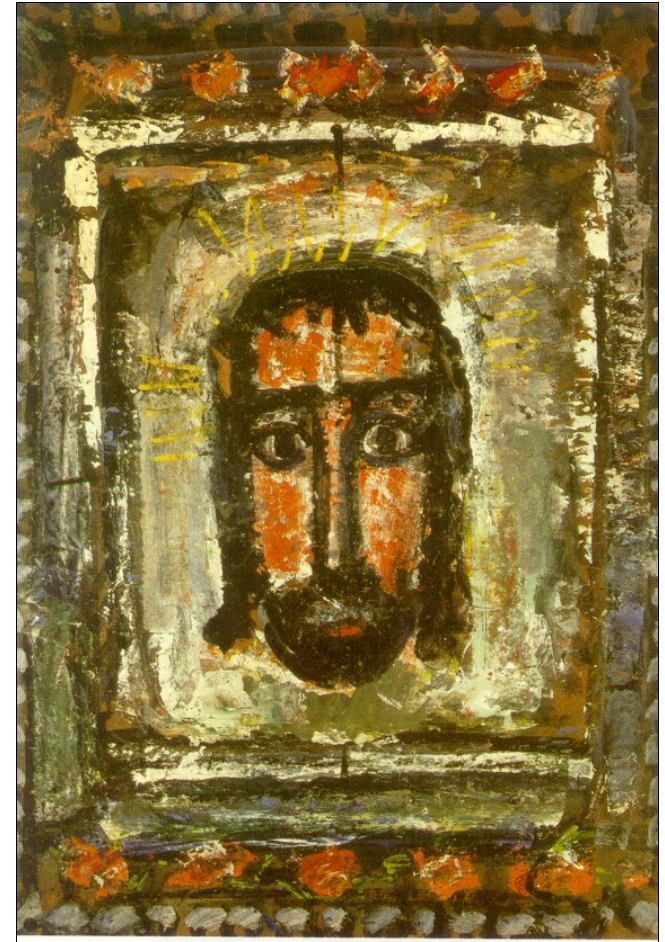

- Ilustr. 5. G. Rouault, La santa faz, 1933.

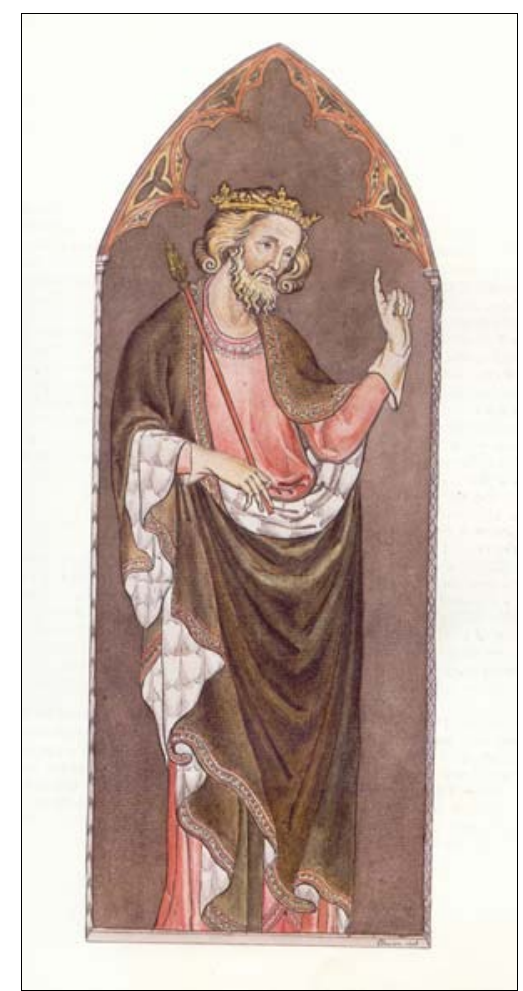

Ilustr. 7. W. Blake, Rey Sebert, ca. 1775 .

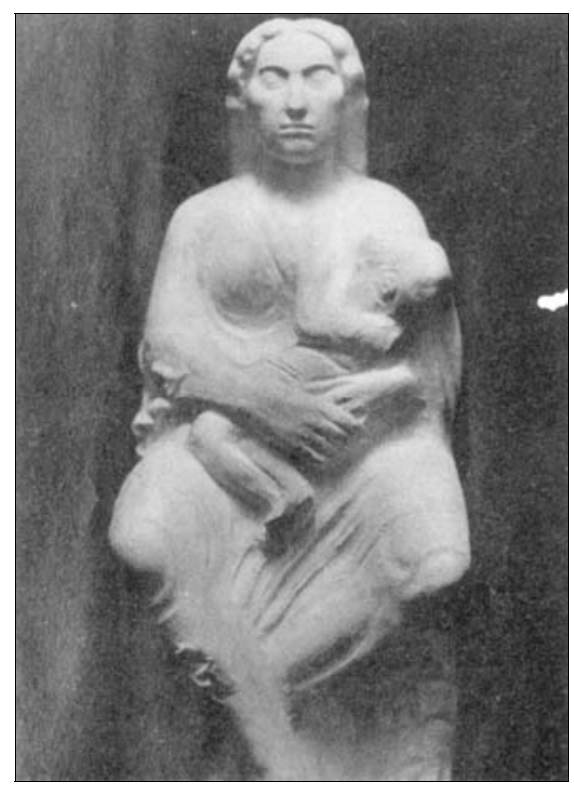

- Ilustr. 6. F. Asorey, Mater, ca. 1916 (Tomada de R. OTERO TÚÑEZ, “O escultor Asorey. Vida e Obra", Centenario Francisco Asorey, Santiago de Compostela, 1989).

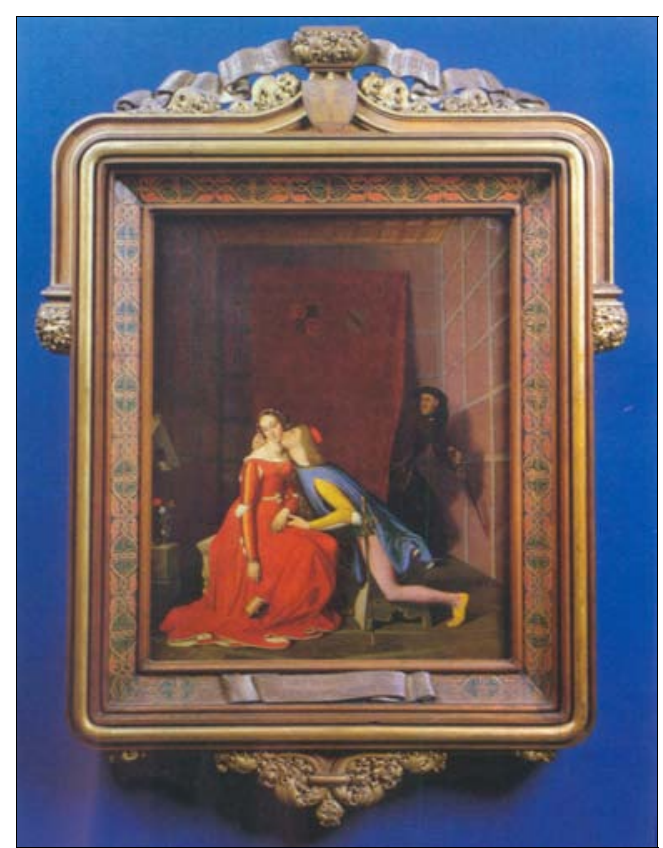

- Ilustr. 8. J. D. Ingres, Paolo et Francesca, 1819. 


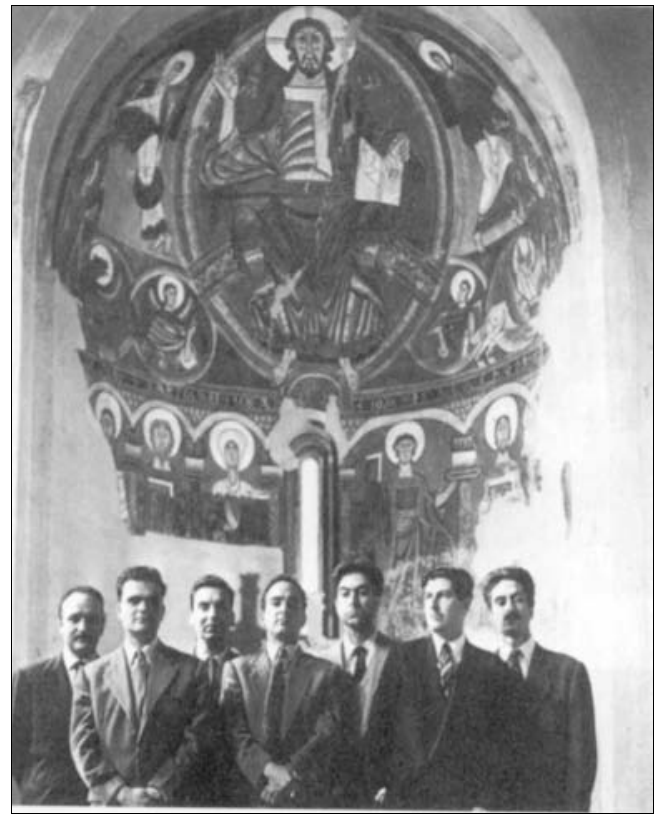

- Ilustr. 9. Grupo Tahull, fotografía realizada por Francesc Cátala Roca en 1955 (Tomada de: J.L. FERRIER, El arte del siglo XX. 1950-1990, Barcelona, 1990).

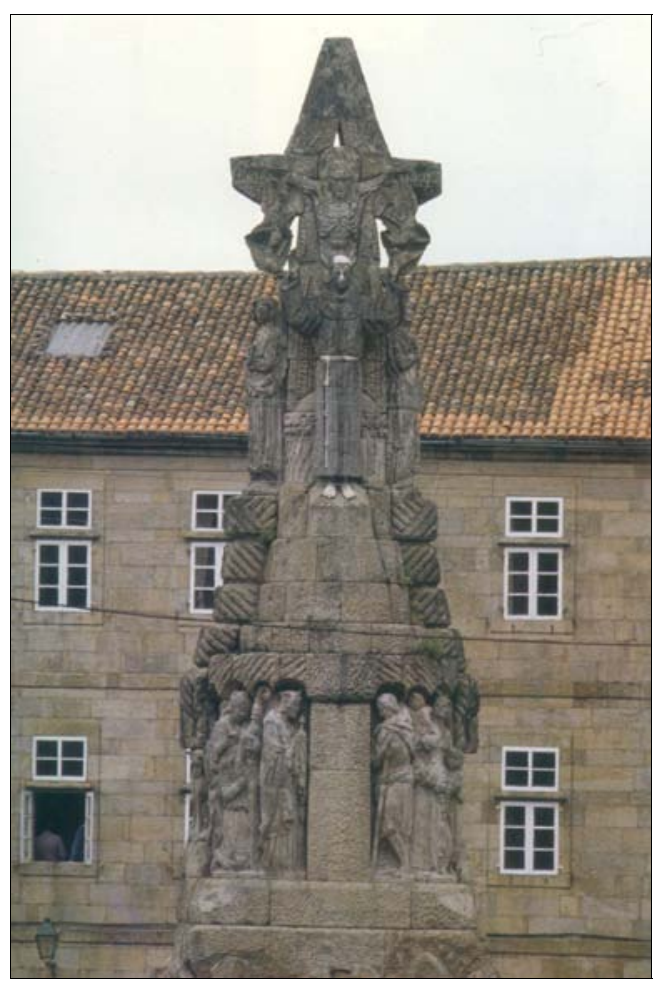

- Ilustr. 10. F. Asorey, Monumento a San Francisco (Santiago de Compostela), 1926-30. 